\begin{tabular}{lll}
\hline \hline Vol. 128 & OCTOBER 2002 Part B & No. 586 \\
\hline \hline
\end{tabular}

\title{
Is the Gulf Stream responsible for Europe's mild winters?
}

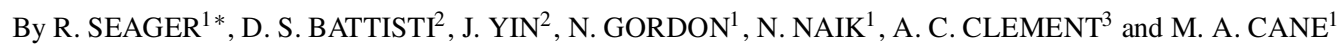 \\ ${ }^{1}$ Lamont Doherty Earth Observatory of Columbia University, USA \\ ${ }^{2}$ University of Washington, USA \\ ${ }^{3}$ Rosenstiel School of Marine and Atmospheric Sciences, USA
}

(Received 23 July 2001; revised 19 April 2002)

\section{SUMMARY}

Is the transport of heat northward by the Gulf Stream and North Atlantic Drift, and its subsequent release into the midlatitude westerlies, the reason why Europe's winters are so much milder than those of eastern North America and other places at the same latitude? Here, it is shown that the principal cause of this temperature difference is advection by the mean winds. South-westerlies bring warm maritime air into Europe and northwesterlies bring frigid continental air into north-eastern North America. Further, analysis of the ocean surface heat budget shows that the majority of the heat released during winter from the ocean to the atmosphere is accounted for by the seasonal release of heat previously absorbed and not by ocean heat-flux convergence. Therefore, the existence of the winter temperature contrast between western Europe and eastern North America does not require a dynamical ocean. Two experiments with an atmospheric general-circulation model coupled to an ocean mixed layer confirm this conclusion. The difference in winter temperatures across the North Atlantic, and the difference between western Europe and western North America, is essentially the same in these models whether or not the movement of heat by the ocean is accounted for. In an additional experiment with no mountains, the flow across the ocean is more zonal, western Europe is cooled, the trough east of the Rockies is weakened and the cold of north-eastern North America is ameliorated. In all experiments the west coast of Europe is warmer than the west coast of North America at the same latitude whether or not ocean heat transport is accounted for. In summary the deviations from zonal symmetry of winter temperatures in the northern hemisphere are fundamentally caused by the atmospheric circulation interacting with the oceanic mixed layer.

KEYWORDS: European winters

\section{INTRODUCTION}

It is widely believed by scientists and lay people alike that the transport of warm water north in the Gulf Stream and North Atlantic Drift, and its release to the atmosphere, is a major reason why western Europe's winters are so much milder (as much as 15-20 degC) than those of eastern North America (Fig. 1). The idea appears to have been popularized by M. F. Maury in his book The physical geography of the sea and its meteorology (1855) which went through many printings in the United States and the British Isles and was translated into three languages. In the book Maury says:

One of the benign offices of the Gulf Stream is to convey heat from the Gulf of Mexico, where otherwise it would become excessive, and to disperse it in regions beyond the Atlantic for the amelioration of the climates of the British Isles and of all Western Europe. Maury, 1855.

* Corresponding author: Lamont Doherty Earth Observatory of Columbia University, Palisades, New York, NY 10964, USA. e-mail: rich@maatkare.ldeo.columbia.edu

(c) Royal Meteorological Society, 2002. 


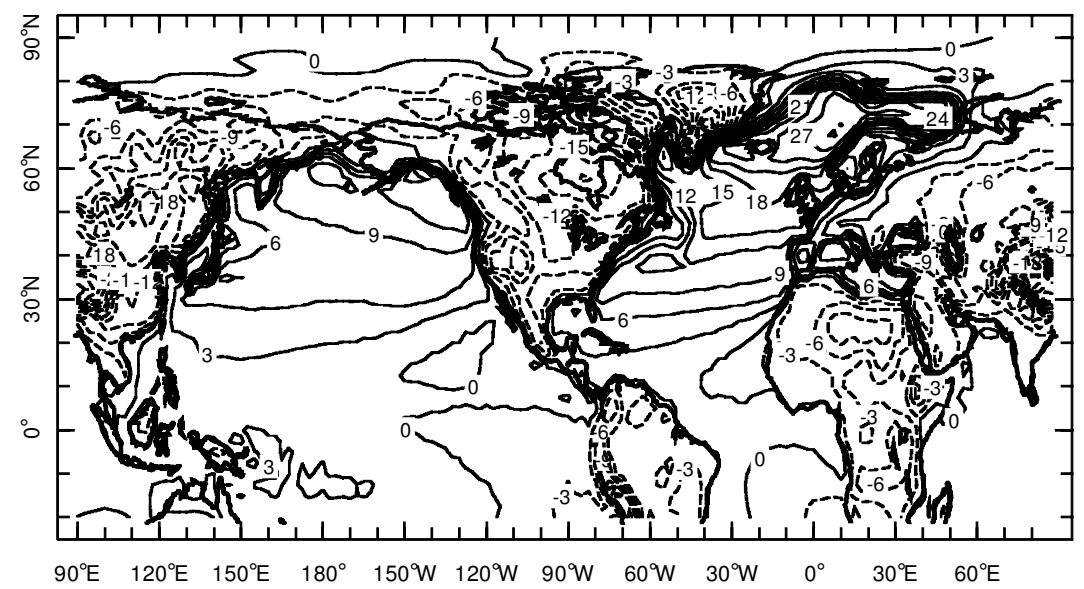

Figure 1. Departure from the zonal mean of January surface air temperature (degC) from NCEP/NCAR Reanalysis. Parts of Western Europe (taken to mean the part of Europe west of the longitude that joins the Adriatic and the Baltic), are 15-20 degC warmer than parts of eastern North America and are also warmer than western North America at the same latitudes. The contrast is greatest in the maritime regions of north-west Europe (the British Isles and Scandinavia). The contour interval is $3 \mathrm{degC}$ with negative values dashed.

Maury says that were this not to occur:

the soft climates of both France and England would be as that of Labrador, severe in the extreme, and ice-bound. Maury, 1855.

He continues:

Every west wind that blows crosses the stream on its way to Europe, and carries with it a portion of this heat to temper there the northern winds of winter. It is the influence of this stream upon climate that makes Erin the 'Emerald Isle of the Sea', and that clothes the shores of Albion in evergreen robes; while in the same latitude, on this side, the coasts of Labrador are fast bound in fetters of ice. Maury, 1855.

The idea that the poleward ocean heat transport (OHT) helps make western Europe's winters the mildest of their latitude has gained wide currency, with the subtle difference that the poleward flow of warm water is now more likely to be ascribed to the thermohaline circulation (THC) than the Gulf Stream per se. For example, in a recent paper about the possible impact of rising greenhouse gases on the THC, Latif et al. state:

In the North Atlantic the Gulf Stream transports enormous amounts of heat poleward (1 PW) as part of the THC, thereby warming western Europe. Latif et al., 2000.

In a prior paper on the same subject Broecker states:

One of the major elements of today's ocean system is a conveyor-like circulation that delivers an enormous amount of tropical heat to the northern Atlantic. During winter, this heat is released to the overlying eastward moving air masses, thereby greatly ameliorating winter temperatures in northern Europe. Broecker, 1997.

These statements are somewhat ambiguous (warming and ameliorating relative to what?-the ambiguity is consciously echoed in the title of this paper), but both imply that the OHT preferentially affects temperatures in parts of Europe, increasing the zonal temperature asymmetry. Hartmann (1994) explicitly appeals to the OHT as one factor needed to explain why winters in western Europe are milder than those in eastern North America:

It appears that some of the heat carried northward by the Gulf Stream is picked up by the Norwegian Current and carried into polar latitudes. As a result, at middle and high latitudes the 
eastern Atlantic is much warmer at the surface than the western Atlantic Ocean. This asymmetry in the Atlantic sea surface temperature contributes to the milder winter climates of western Europe land areas compared to eastern North American land areas at the same latitude. Another major contribution to this climate asymmetry is the eastward advection of temperature in the atmosphere.

Hartmann, 1994.

As suggested by Hartmann (1994), the contrast between American and west European winters is largely explained by the difference between a continental climate and a maritime climate. Although this is widely accepted, and few researchers would ascribe to the OHT the dominant role attributed to it by Maury, existing explanations of the contrasting winters still generally appeal to the additional influence of the poleward OHT. However, we are unaware of a quantitative demonstration of the relative importance of the three processes that contribute to the east-west asymmetry across the North Atlantic Ocean: northward heat transport by the ocean, the seasonal and local release of heat previously stored by the ocean and advection within the winter stationary waves.

In the current paper we demonstrate that transport of heat by the ocean has little influence on the contrast between the mild winters of western Europe south of $60^{\circ} \mathrm{N}$ and the harsh ones of eastern North America. North of $60^{\circ} \mathrm{N}$ the OHT accounts for about a quarter of the contrast by restricting winter sea-ice cover. The dominant cause of the contrast, at both latitudes, is atmospheric advection around the Icelandic Low and the simple maritime-continental climate distinction. The exact positioning and strength of the Icelandic Low is important to the climate contrast and is shown to be greatly influenced by the orographic forcing of the Rocky Mountains. Therefore, the difference in the winter climates arises fundamentally through atmospheric processes and the seasonal storage and release of heat by the ocean mixed layer. This is also all that is required to establish the difference in winter climates between the west coast of Europe and the west coast of North America at the same latitudes.

In the next section we consider the role of OHT using observational estimates of poleward heat transports, the ocean surface heat-flux balance and an analysis of the heat budget of the lower levels of the atmosphere. We then proceed to describe in section 3 results from integrations of coupled atmospheric general-circulation/mixed-layer ocean (AGCM-ML) models with and without specified ocean heat transports. It will be shown that the OHT does not alter the relative severity of winter climates on either side of the North Atlantic except for regions of northern Norway where it restricts the winter sea-ice cover. We then show results of numerical integrations of one of the AGCMML models in which the mountains are removed. We briefly consider the causes of the different winter climates of the Pacific coast of Canada and Alaska and the Atlantic coast of Europe and conclude that this difference too is not the result of the greater poleward heat transport in the Atlantic Ocean. Sensitivity of the results is discussed in section 4 and the final section summarizes our conclusions.

\section{ObSERVATional ANAlysis of North Atlantic Winter Climate}

\section{(a) The relative roles of atmosphere and ocean in poleward heat transport}

If the atmosphere and ocean did not move heat from the Tropics to midlatitudes, both North America and Europe would be much colder than they are. First, we look at how this heat transport is partitioned between atmosphere and ocean.

Trenberth et al. (2001) have used recent reanalysis products from the National Centers for Environmental Prediction (NCEP) and the European Centre for MediumRange Weather Forecasts (ECMWF) to derive new estimates of the atmospheric and oceanic energy transports. They directly computed the atmospheric transports from the 


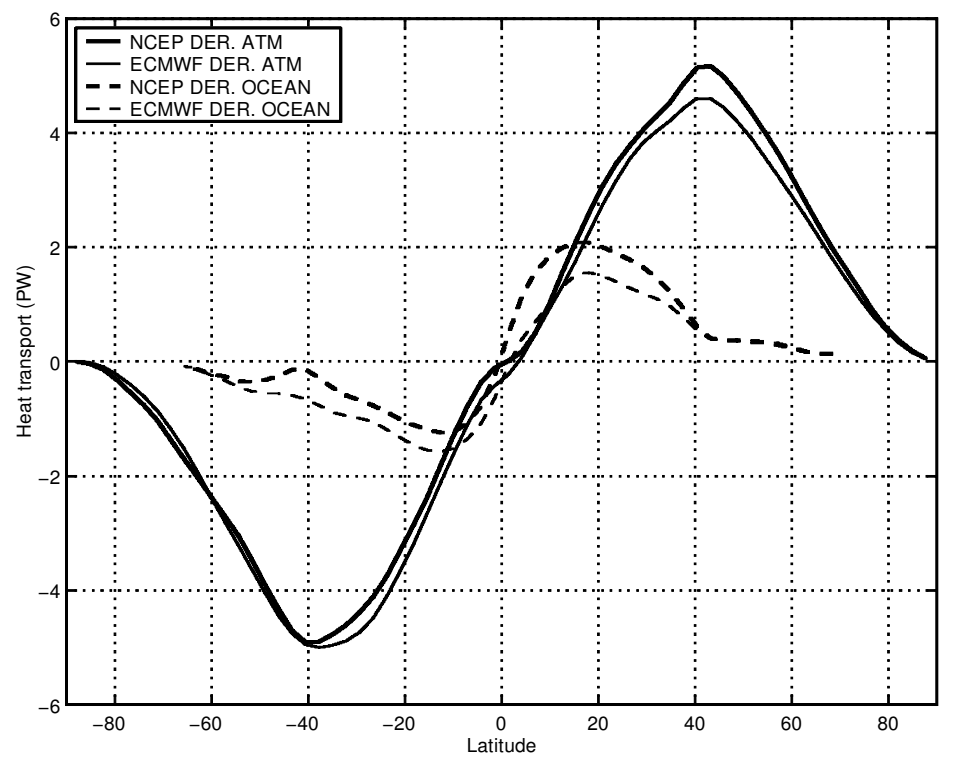

Figure 2. Estimated zonally averaged atmospheric (solid lines) and oceanic (dashed lines) northward heat transports as computed from NCEP (thick lines) and ECMWF (thin lines) reanalyses (see Trenberth et al. (2001) for more details and http://www.cgd.ucar.edu/cas/catalog/tn430 where the data resides). The heat transports are in petawatts.

reanalyses and used these, in combination with satellite estimates of the net radiation at the top of the atmosphere, to derive the implied surface fluxes and zonally and annually averaged ocean heat transports. The estimates are shown in Fig. 2. The ocean and atmosphere poleward transports are equal at about $15^{\circ} \mathrm{N}$ and $15^{\circ} \mathrm{S}$, with the ocean moving more in between, and an increasingly small proportion poleward of those latitudes. In the midlatitudes the annual mean atmospheric heat transport exceeds the ocean transport by a factor of five or so. The dominance of the atmosphere is far greater than earlier estimates (e.g. Peixoto and Oort 1992) which gave more weight to the ocean. Trenberth and Caron (2001) have compared their results to direct estimates in the ocean and those derived using an inverse method by Ganachaud and Wunsch (2000), and show that the NCEP-derived estimates fall within the error bars of those estimates in the subtropics while the ECMWF-derived estimates are clearly too low. North of $40^{\circ} \mathrm{N}, \mathrm{NCEP}$ and ECMWF estimates agree with each other and with independent direct estimates. Interestingly, these recent estimates are in quantitative agreement with the early estimates of Houghton (1954) and Sverdrup (1957) as presented by Bjerknes (1964).

Clearly, the atmosphere is doing the lion's share of the poleward heat transport required to ameliorate climates at midlatitudes. This will be even more so in northern winter when the atmospheric heat transport is greater than its annual mean while the OHT appears to be less than its annual mean (see later)*.

* In the model experiments described here, the surface temperatures of the area north of $35^{\circ} \mathrm{N}$ varied as the OHT changed according to a climate sensitivity of about $2 \mathrm{~W} \mathrm{~m}^{-2} \mathrm{~K}^{-1}$. Given this sensitivity, the winter atmospheric heat transport across $35^{\circ} \mathrm{N}$ of about $6 \mathrm{PW}$ (equivalent to $54 \mathrm{~W} \mathrm{~m}^{-2}$ for the area north of there) warms the area to the north by about $27 \mathrm{degC}$. The global OHT across the same latitude (about $1.3 \mathrm{PW}$ ) would warm the area to the north by about $6 \operatorname{deg} \mathrm{C}$. 


\section{(b) Maintenance of the zonal asymmetries of northern hemisphere winter temperatures}

To look more closely at the causes of the zonal asymmetries of temperature in the lower atmosphere during northern hemisphere winter we turned to an analysis of the balance of terms in the vertically integrated thermodynamic energy equation:

$$
\begin{aligned}
-\left\{\frac{\bar{u}}{a \cos \theta} \frac{\partial \bar{T}}{\partial \lambda}+\frac{\bar{v}}{a} \frac{\partial \bar{T}}{\partial \theta}\right\}-\bar{\omega}\left\{\frac{\partial \bar{T}}{\partial p}-\frac{R \bar{T}}{p c_{p}}\right\} \\
-\left\{\frac{1}{a \cos \theta} \frac{\partial\left(\overline{u^{\prime} T^{\prime}}\right)}{\partial \lambda}+\frac{1}{a} \frac{\partial\left(\overline{v^{\prime} T^{\prime}}\right)}{\partial \theta}\right\}-\left\{\frac{\partial\left(\overline{\omega^{\prime} T^{\prime}}\right)}{\partial p}-\frac{R}{p c_{p}} \overline{\left(\overline{\omega^{\prime} T^{\prime}}\right)}\right\}=-\bar{Q} .
\end{aligned}
$$

The budget is then integrated from $70000 \mathrm{~Pa}$ to $100000 \mathrm{~Pa}$ and then averaged over December to February. The overbars denote the monthly mean and primes denote departures from the monthly mean. Hence the transient terms include everything on submonthly time-scales. In Eq. (1) $u, v$ and $\omega$ are the zonal, meridional and vertical pressure velocities, respectively, $T$ is temperature, $a$ is the radius of the earth, $\theta$ is latitude, $\lambda$ is longitude, $p$ is pressure, $R$ is the gas constant and $Q$ is the diabatic heating.

The first two terms are the stationary advection, including the zonal mean, by the horizontal flow and the stationary vertical advection. The third term is the horizontal transient-eddy heat-flux convergence and the fourth term is the vertical transient-eddy heat-flux convergence. The diabatic heating $Q$ is evaluated as the residual. All terms are converted to $\mathrm{W} \mathrm{m}^{-2}$. Calculations were performed using the NCEP Reanalyses from 1949 to 2000 (Kalnay et al. 1996). Horizontal derivatives were evaluated using centred differences and the vertical integrals were approximated using data at 1000, 925, 850, 700 and $600 \mathrm{mb}$ assigning each level value to a layer.

Figures 3-5 show the terms in the temperature equation. The stationary horizontal advection (Fig. 3(a)) creates the America-north-west Europe contrast. Horizontal transient heat fluxes (Fig. 3(b)) act to oppose the asymmetry by warming north-eastern North America and cooling western Europe. The cooling of north-eastern North America by the stationary advection appears as a stronger feature than the warming of western Europe. Similar asymmetries also appear across the Pacific Ocean. The term involving the mean vertical velocity (Fig. 4(a)) is a cooling in the region of the Pacific coast of North America opposing the warming by horizontal advection. The transient vertical fluxes (Fig 4(b)) act to cool the North Atlantic and North Pacific Oceans and in both cases by more in the west than in the east. The diabatic heating (Fig. 5) of the lower levels of the atmosphere is strong in the Gulf Stream and Kuroshio regions and is positive over most of the North Atlantic and North Pacific Oceans. East of North America the diabatic heating, which reaches $150 \mathrm{~W} \mathrm{~m}^{-2}$, is partly balanced by stationary advective cooling and partly by transient-eddy heat-flux divergence. Consequently, release of some of the heat converged by the ocean into the Gulf Stream region is used by transient eddies to dissipate the east-west climate asymmetry. Immediately west of western Europe the net diabatic heating of the lower part of the atmosphere is about $30-60 \mathrm{~W} \mathrm{~m}^{-2}$, indicating that the surface sensible and radiative heating plus condensational heating is more closely balanced by radiative cooling of the layer.

All of these features of the stationary advection, transient heat flux and diabatic heating have their analogues over the Pacific Ocean and explain why winters in eastern Asia are so much colder than those in western North America.

All the patterns are very similar to those presented by Lau (1979) and the results appear to be robust: stationary advection creates the situation whereby winters in 
(a)

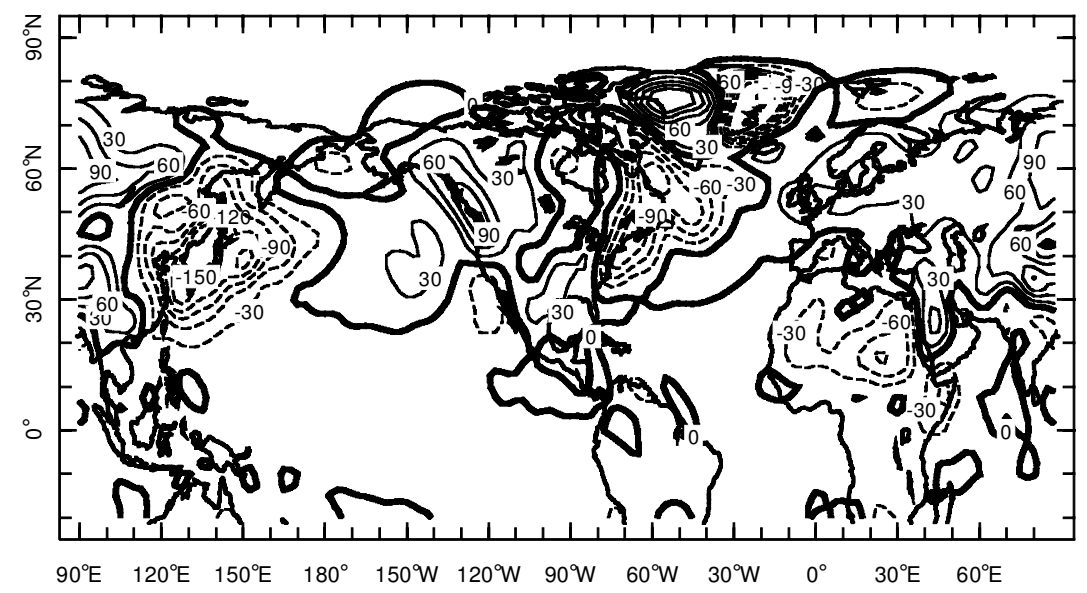

(b)

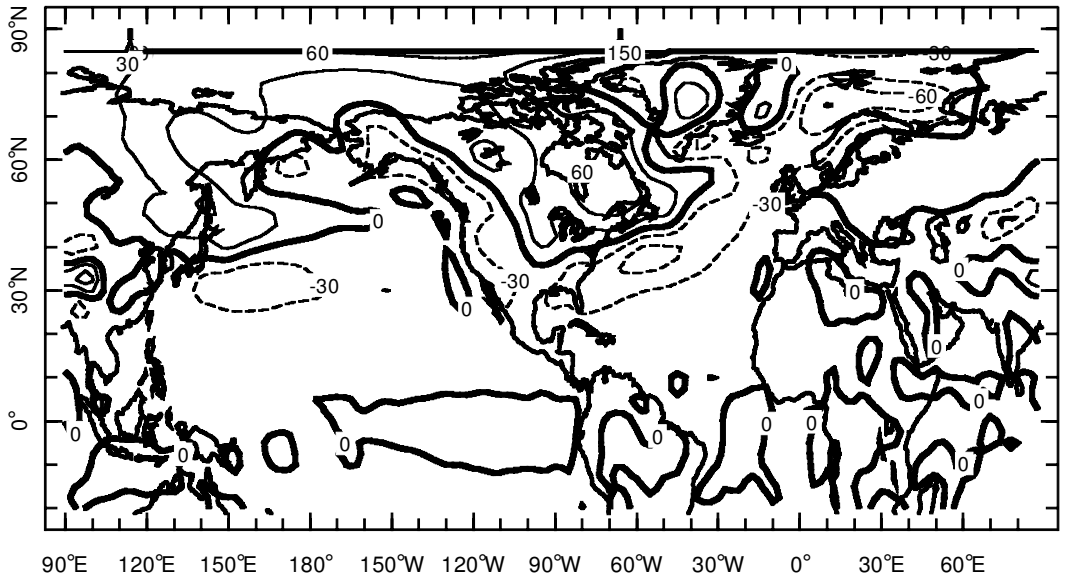

Figure 3. Terms in the temperature equation, vertically integrated from 700 to $1000 \mathrm{mb}$ and averaged from December to February. (a) The stationary horizontal advection of temperature, and (b) the convergence of transient-eddy horizontal sensible-heat flux. Terms are evaluated from NCEP Reanalyses for the 1949 to 2000 period. All terms are in $\mathrm{W} \mathrm{m}^{-2}$, the contour interval is $30 \mathrm{~W} \mathrm{~m}^{-2}$, with a thick line for the zero contour and negative values dashed.

western Europe are warmer than those in north-eastern North America while transient heat fluxes attempt to damp this asymmetry (see also Hoskins and Valdes (1990)).

The zonal and meridional contributions to the stationary horizontal advection are shown in Figs. 6(a) and (b). Cold air resides over North America and, over the North Atlantic, the isotherms tilt from south-west to north-east, with cool air on their northwestern side. Zonal advection by the mean westerlies therefore cools eastern North America and the Atlantic Ocean until quite close to the European coast. The air temperature has a longitudinal maximum just west of the European coast and east of here the zonal advection warms western Europe. Meridional advection cools central North America but warms the central North Atlantic where the mean flow has a southerly component. The meridional advection is therefore creating the south-west to north-east tilt of the isotherms that allows the zonal advection to adopt its particular 
(a)

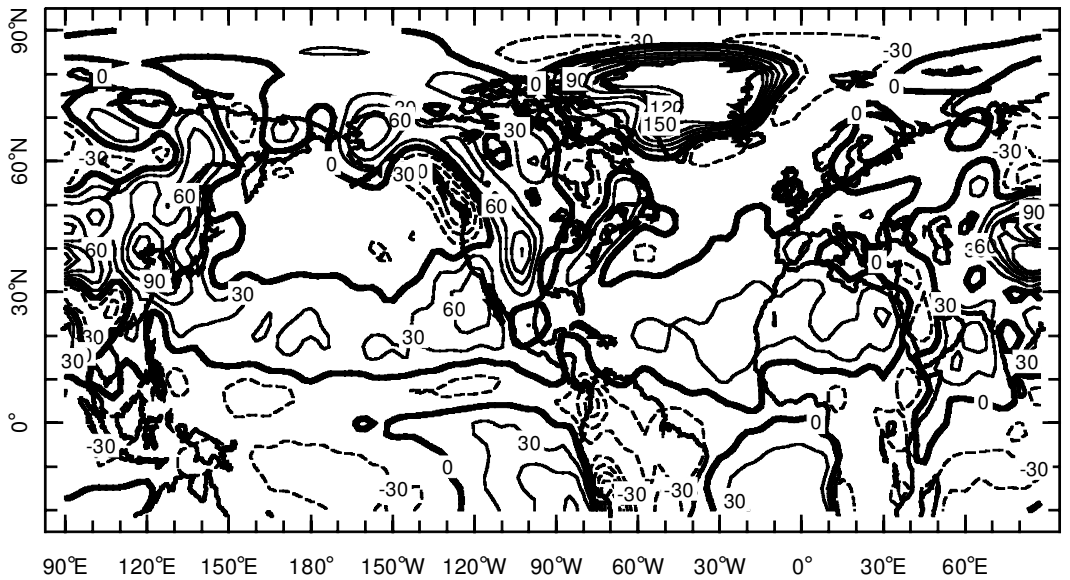

(b)

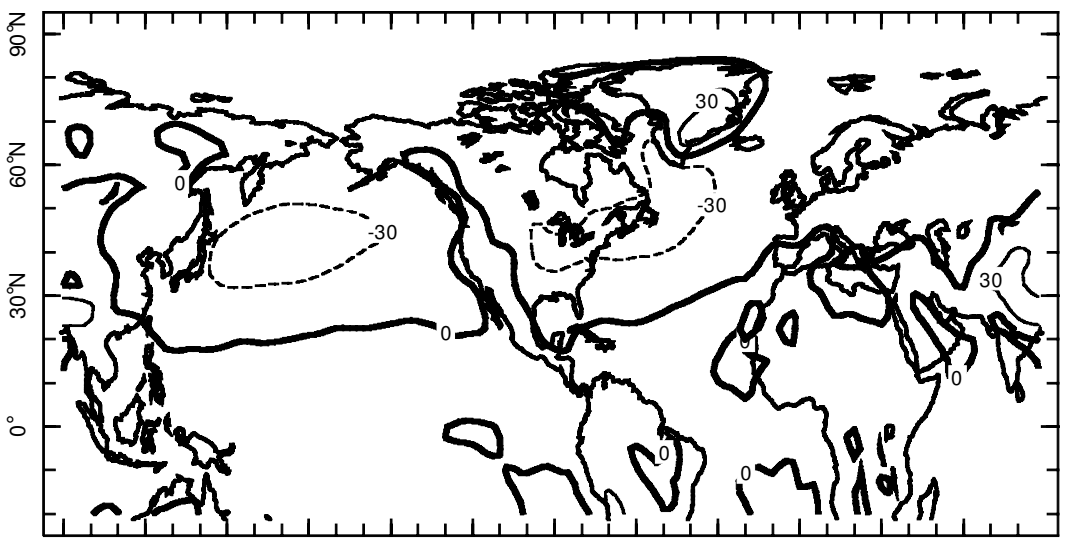

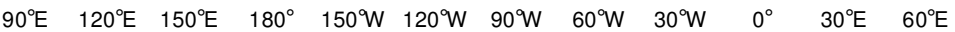

Figure 4. As Fig. 3 showing (a) the stationary vertical advection of temperature and adiabatic heating, and (b) the convergence of transient-eddy vertical advection and adiabatic heating.

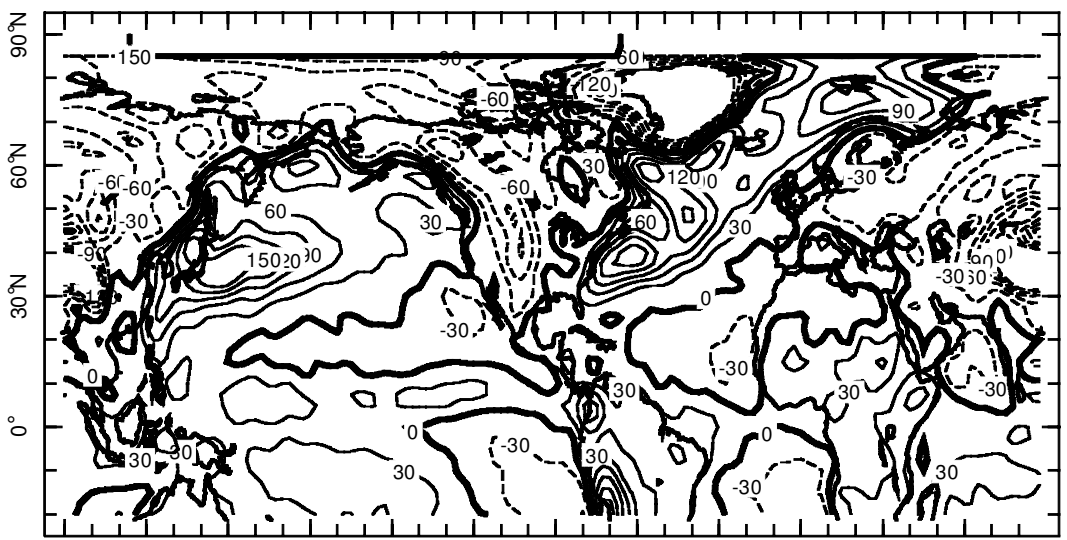

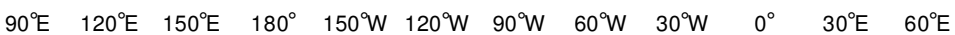

Figure 5. As Fig. 3 but showing the diabatic heating. 
(a)

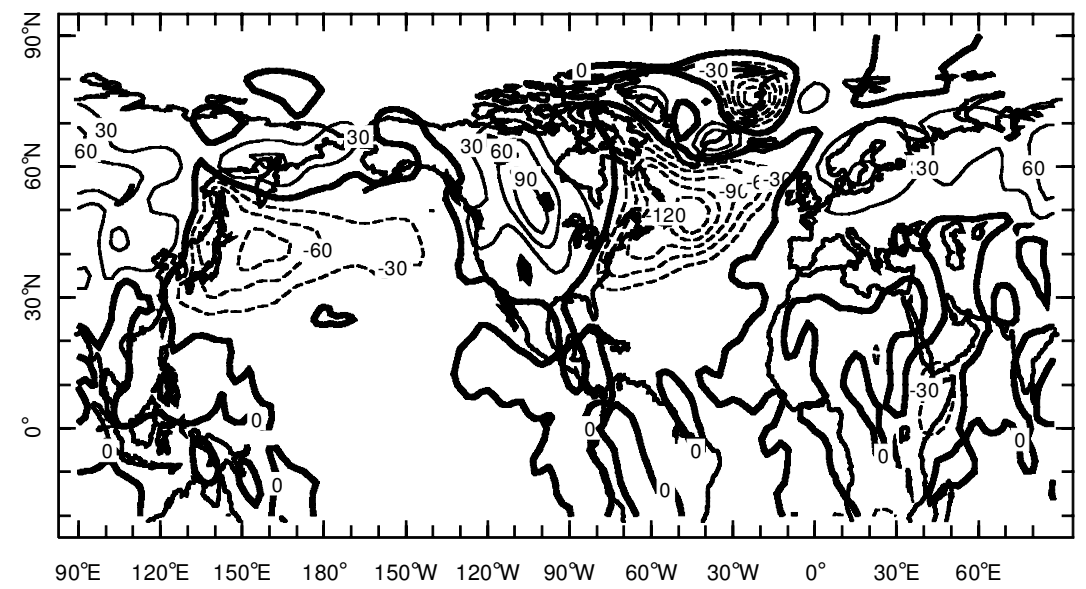

(b)

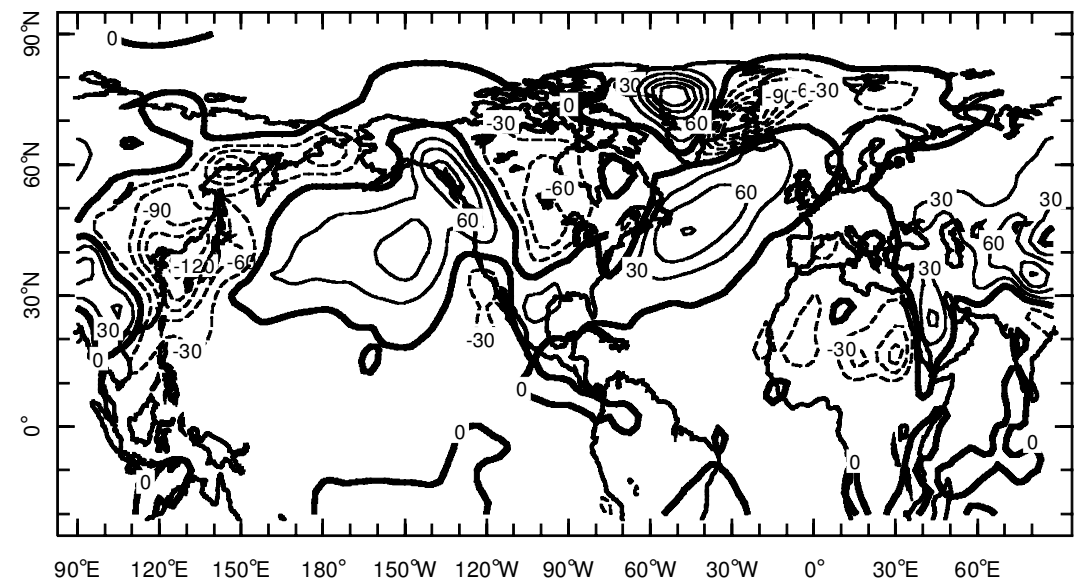

Figure 6. Stationary advective terms in the temperature equation, vertically integrated from 700 to $1000 \mathrm{mb}$. (a) The zonal advection of temperature and (b) the meridional advection of temperature. The contour interval is $30 \mathrm{~W} \mathrm{~m}^{-2}$, with the a thick line for the zero contour and the negative values dashed.

pattern and, in sum, provide the pattern of net stationary heating and cooling seen in Fig. 3(a).

In summary, the east-west asymmetry of winter climates on the seaboards of the North Atlantic is created by north-westerly advection over eastern North America and by zonal advection into Europe. The Pacific Ocean has an analogous arrangement with meridional advection being an especially strong cooling over Asia. Since western Europe is indeed warmed by westerly advection off the Atlantic, we next assess how the surface fluxes over the Atlantic are maintained.

(c) Relative contribution of ocean heat-flux convergence to seasonal release of heat over the North Atlantic Ocean

Large amounts of heat are released to the atmosphere from the North Atlantic Ocean during winter. Of primary interest here is how the maintenance of this winter heat release divides up between release of heat converged by the ocean and release 
of heat stored locally by the ocean in summer months. We are still a long way from knowing the seasonal and latitudinal and longitudinal distribution of ocean heat-flux convergence accurately because our knowledge of the surface fluxes and the seasonal changes in ocean heat storage is incomplete. However, Hsiung et al. (1989) have used surface observations and US Navy temperature-profile data to compute the monthly and latitudinal distribution of zonally averaged poleward heat transports*. Hsiung et al. show that, for the North Atlantic, at $40^{\circ} \mathrm{N}$ for example, the ocean moves $1 \mathrm{PW}$ of heat north during March through October but only 0.5 PW during winter (their Fig. 8). This seasonal distribution is not unreasonable given that when the midlatitude westerlies are blowing in full force during winter they drive a southward Ekman drift that cools the ocean while, in summer, the northward heat transport by the geostrophic gyres and the thermohaline circulation is relatively unopposed. The same seasonal cycle, with considerably stronger northward heat transport in the Atlantic Ocean during summer between $10^{\circ} \mathrm{N}$ and $50^{\circ} \mathrm{N}$, has been found in wind-forced ocean general-circulation models (Boning and Herrmann 1994; Chassignet et al. 1996). These models show that there is larger ocean heat-flux convergence in the Atlantic north of $40^{\circ} \mathrm{N}$ in summer than in winter. In the annual mean the net surface heat flux must be very nearly balanced by the ocean heat-flux convergence. By the reasoning above, the annual mean ocean heat-flux convergence should be an upper bound on the wintertime ocean heat-flux convergence, as is true in the extratropics of the model studies cited. This wintertime ocean heat-flux convergence is responsible for a portion of the wintertime heat release from the ocean to the atmosphere; the remainder is maintained by the balance between reduction of heat stored in the ocean and absorption of solar radiation. Hence we can write

$$
Q_{\mathrm{O} \rightarrow \mathrm{A}}^{\text {winter }}=\mathrm{OHC}+Q_{\mathrm{O} \rightarrow \mathrm{A}}^{\text {local }}
$$

Here, $Q_{\mathrm{O} \rightarrow \mathrm{A}}^{\text {winter }}$ is the wintertime heat release from ocean to atmosphere and equals the sum of sensible-, latent- and long-wave-radiative heat loss, $\mathrm{OHC}$ is the ocean heatflux convergence and $Q_{\mathrm{O} \rightarrow \mathrm{A}}^{\mathrm{local}}$ is the release of heat due to local processes of reduction of heat storage and absorption of solar radiation. Figure 7 shows these three quantities estimated from the surface marine data of DaSilva et al. (1994). The total winter heat release has a maximum in the Gulf Stream region, west of $35^{\circ} \mathrm{W}$, where it can reach $400 \mathrm{~W} \mathrm{~m}^{-2}$. The heat release is much less elsewhere. The annual mean ocean heat-flux convergence also has a maximum in the Gulf Stream region where it is about $50 \%$ of the total heat release. The ocean heat-flux convergence also accounts for up to $50 \%$ of the winter heat release in the subpolar North Atlantic north of Norway. Outside these two regions the winter heat release is largely accounted for by the local release of absorbed solar radiation and heat previously stored. These comparisons indicate that for most of the North Atlantic the processes of ocean heat-flux convergence play a secondary role to local processes in maintaining the wintertime heat release from ocean to atmosphere. This is consistent with the early estimates of Gill and Niiler (1973, pp. 147-148). The partitioning of the winter heat release between ocean heat-flux convergence and seasonal storage appears very similar in other surface flux data (from NCEP reanalyses (Kalnay et al. 1996) as well as the Southampton Oceanography Centre (Josey et al. 1998) and Oberhuber (1988), both of which, like DaSilva et al., are based on ship reports but using different analysis procedures). It is noticeable that the ocean heat-flux convergence is more localized in the Gulf Stream and Norwegian Sea than the seasonal heat release.

\footnotetext{
* Our own attempts to do this with the independent data of Levitus and Boyer (1994) led to very noisy estimates presumably due to dubious heat storage data that Hsiung et al.'s analysis procedures were able to overcome.
} 
(a)

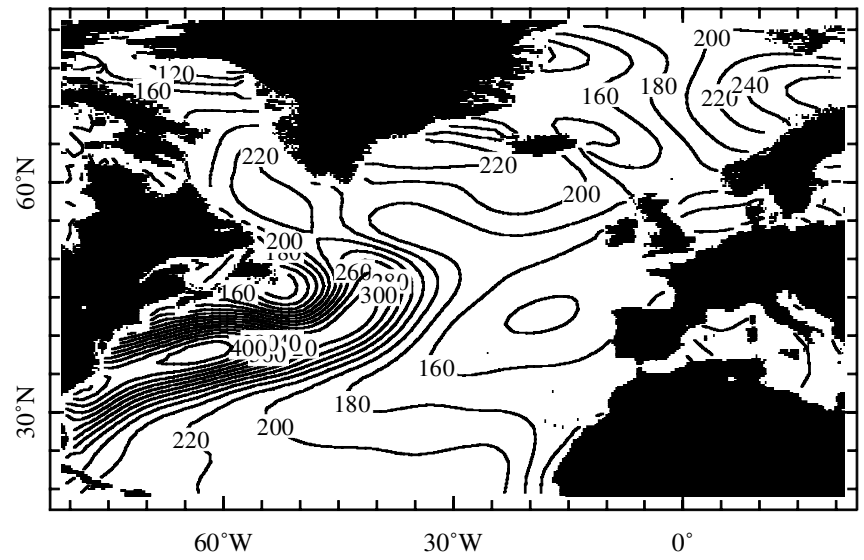

(b)

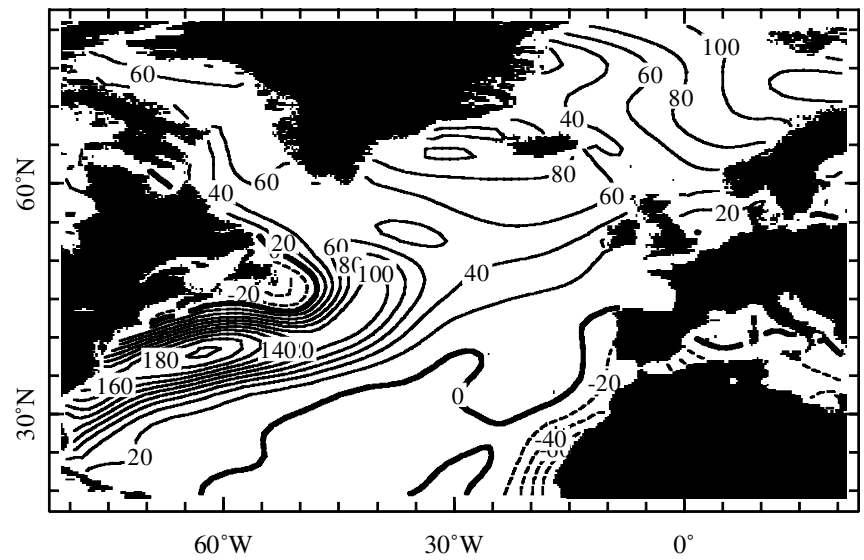

(c)

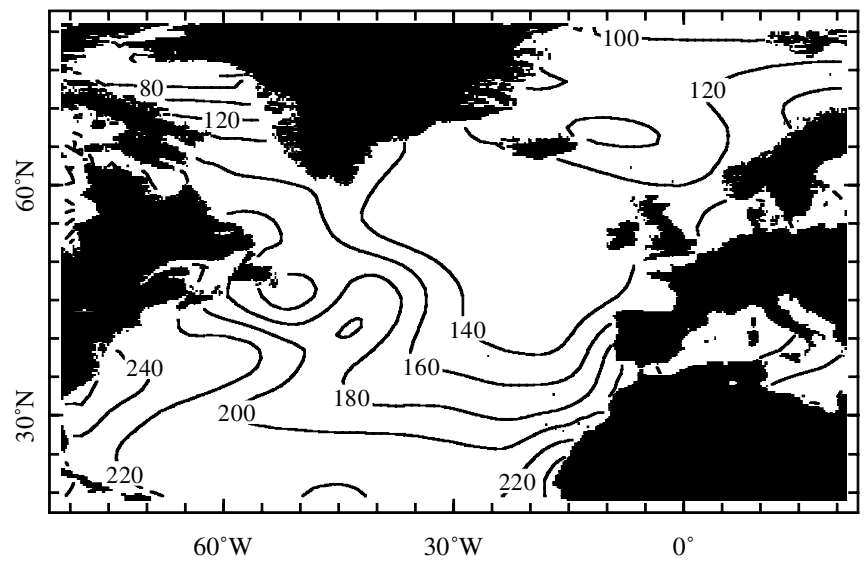

Figure 7. (a) The total release of sensible, latent and radiative heat from the ocean to atmosphere, averaged over December to February. (b) The annual mean net surface heat flux, taken to equal the annual-mean ocean heatflux convergence which is assumed to be an upper bound on the wintertime ocean heat-flux convergence. (c) The difference between (a) and (b) which is the heat released from the ocean to atmosphere due to reduction of heat storage and absorption of solar radiation. All terms are in $\mathrm{W} \mathrm{m}^{-2}$. Data are from the surface marine analysis of DaSilva et al. (1994). 
If the Atlantic OHT across $35^{\circ} \mathrm{N}$ is $0.8 \mathrm{PW}$ (the value used in the models described below and consistent with observational estimates), then it sustains a mean net surface heat flux out of the Atlantic Ocean north of there of $37 \mathrm{~W} \mathrm{~m}^{-2}$. This is small compared with the area average of the seasonal heat release (net surface heat flux minus the contribution by ocean heat-flux convergence) which is $135 \mathrm{~W} \mathrm{~m}^{-2}$. The seasonal heat release from both the Pacific and the Atlantic north of $35^{\circ} \mathrm{N}$, weighted to account for the partial area of ocean, is $53 \mathrm{~W} \mathrm{~m}^{-2}$. This should be compared with the $11 \mathrm{~W} \mathrm{~m}^{-2}$ contributed by the $1.3 \mathrm{PW}$ heat transport by the Atlantic and Pacific Oceans across $35^{\circ} \mathrm{N}$. Given the typical climate sensitivity, the seasonal heat storage and release warms winters, in the zonal mean, by about $27 \mathrm{degC}$ (equal to the warming due to atmospheric heat transport calculated in section 2(a)). This warming will be greatest over the ocean, giving rise to the obvious land-sea temperature contrast. Thus, according to these simple estimates, the absolute zonal-mean temperatures are maintained by the seasonal heat release from the ocean, the atmospheric heat transport and OHT in the ratio $4.5: 4.5: 1$.

It is interesting to note that the total heat release from ocean to atmosphere is a maximum east of North America, where the atmosphere is cold, and much less west of western Europe, where the atmosphere is warm. This is explained in terms of the low-level atmospheric circulation. The Icelandic Low brings cold dry air off the North American continent and over the relatively warm ocean causing large surface fluxes. To the east, circulation around the Low brings warm, moist air from the south-west towards western Europe and reduces the heat flux from the ocean to the atmosphere. This arrangement of winds, surface fluxes and SSTs is consistent with the atmosphere forcing the ocean's temperature distribution. The position of the Icelandic Low is consistent with the idea of a thermally forced stationary wave whereby the atmospheric heating east of North America is balanced by advective cooling which requires low pressure to the east (Smagorinsky 1953; Hoskins and Karoly 1981). However, as we shall see in section 3(c), the location of the surface low-pressure system is also influenced by the net effect of forcing of stationary waves by the Rocky Mountains.

In summary, the observational data indicate: in midlatitudes the atmospheric heat transport greatly exceeds the OHT; east-west differences in surface air temperature and the south-west/north-east tilt of isotherms of SST appear to be driven by advection of the mean temperatures by the mean atmospheric flow, and the winter surface heat release from the Atlantic Ocean is primarily due to the release of heat stored locally and, to a much lesser extent, OHT.

\section{MOdel RESUltS}

The observational analyses suggest that OHT should have only a modest impact on both absolute temperatures and the zonal asymmetries of temperatures in the wintertime midlatitude northern hemisphere. To test this we performed a pair of experiments with an atmospheric general-circulation model (GCM) coupled to a uniform depth mixedlayer ocean. In one experiment we specify a seasonally and spatially varying 'q-flux' which has been diagnosed as that required for the model to reproduce the observed SST. The annual mean q-flux equals the annual mean implied OHT. However, because the ocean mixed-layer depth is held fixed, the seasonally varying part of the q-flux accounts for not just the seasonal variations of OHT but also exchange of heat with water below that occurs in nature as the mixed-layer depth changes. In the other experiment we set the q-flux to zero so that the SST is determined by surface heat fluxes alone and, in equilibrium, the annual-mean net surface heat flux must be zero. In both experiments the sea-ice cover was held fixed at its annual-mean value in order to eliminate feedbacks 


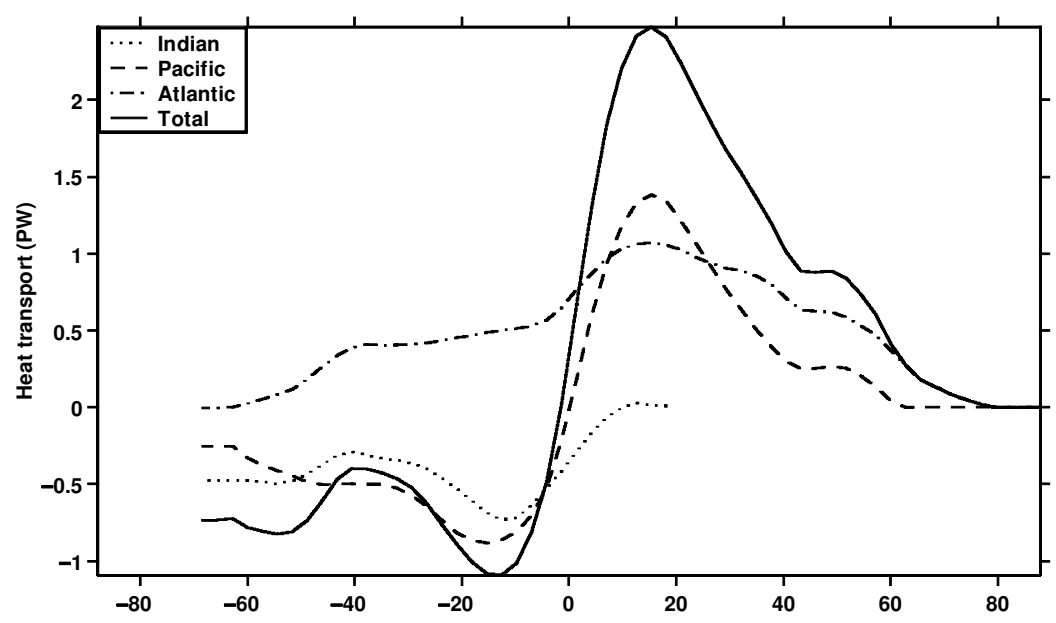

Figure 8. The northward ocean heat transport for the three ocean basins, and their sum, as implied by the annual mean of the CCM3 model q-flux.

between OHT and sea ice and allow comparison with the results obtained from a different model that includes this feedback. Results are for the average of the last 8 years of 15 year integrations by which time the SSTs are in equilibrium.

The model used is the NCAR Community Climate Model Version 3 (NCAR CCM3) with a triangular truncation at wave number 42 and 18 vertical levels. The model has an extensive suite of physical parametrizations of the type that are often referred to as 'state-of-the-art'. The ability of the model to simulate the current climate is extensively documented in papers by Kiehl et al. (1998) and other authors in the same issue of the Journal of Climate.

Figure 8 shows the northward OHTs for the three ocean basins, and for the total, implied by the model q-flux. The maximum northward transport at about $15^{\circ} \mathrm{N}$ is about 10-20\% too large. Compared to Trenberth and Caron's (2001) estimates the implied northward heat transport is also too large in the midlatitude North Atlantic. Differences occur because the errors in the modelled surface fluxes are absorbed into the q-flux. This means that in the control run, with the q-flux, the ocean is accounting for a larger proportion of the poleward heat flux than is probably the case in nature, and the difference between that experiment and the case without the q-flux should bound the upper range of the possible impacts of OHT for the case of fixed sea-ice cover.

Clement and Seager (1999) performed the same experiments with the Goddard Institute for Space Studies (GISS) GCM, a grid-point model described by Hansen et al. (1984) and DelGenio et al. (1996). The resolution is $4^{\circ}$ latitude by $5^{\circ}$ longitude with nine vertical levels. The model has an ocean mixed layer with a specified seasonally and spatially varying depth as in Russell et al. (1985). The mixed layer exchanges heat with a layer below such that, in this model, the q-flux accounts for the implied OHT alone. The GISS model also includes a thermodynamic sea-ice model so the sea-ice extent was allowed to adjust when the specified OHT was removed. The experiments were run for 30 years, by which time the SSTs and sea ice were in equilibrium, and results are shown for averages over the last five years. 


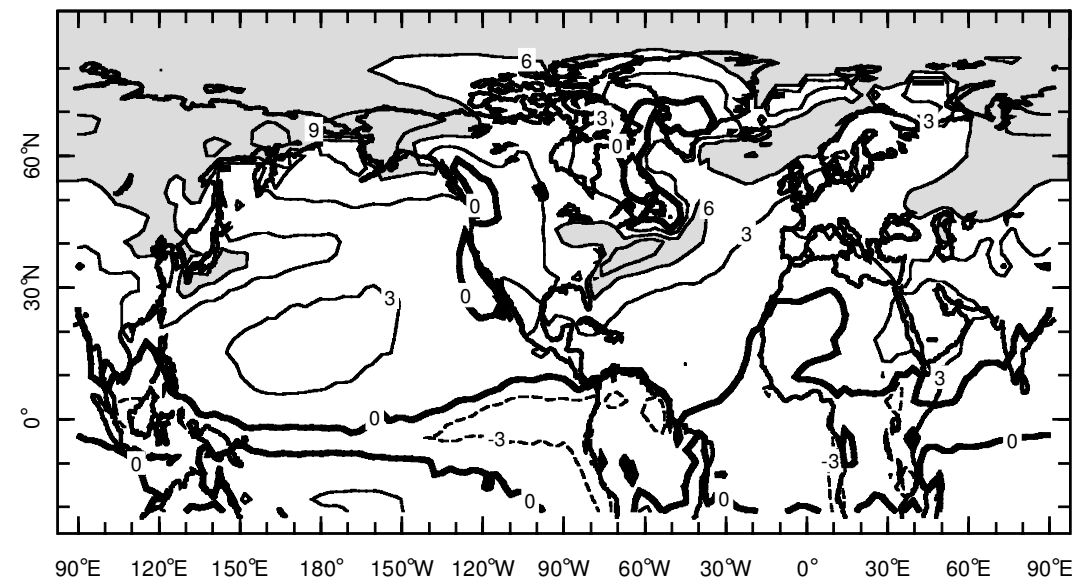

Figure 9. The difference in January surface temperature as simulated by the CCM3 AGCM-ML model for the case with a specified OHT minus the case with no OHT (see text). The contour interval is 3 degC, the thick line marks the zero contour, negative values are dashed and values greater than 6 degC are shaded.

(a) Contribution of ocean heat transport to winter temperatures in the northern hemisphere

Figure 9 shows the difference in January surface temperature for the case without OHT minus the case with, as simulated by CCM3. (Surface temperature is shown here, allowing us to see the SST, but the same conclusions follow from looking at lower-tropospheric temperatures). Removing the OHT warms the equatorial regions but cools everywhere else, as expected. The cooling is already large (about $3 \mathrm{deg} C$ ) in the subtropics but there are regions of stronger cooling in the Gulf Stream and Kuroshio regions and in the far North Atlantic near Iceland where it is above 6 degC.

The temperature change is quite zonally uniform. In the North Atlantic sector removing the global OHT cools much of Western Europe (the British Isles, Scandinavia, France and Germany) by an average of $3 \operatorname{deg} C$ and by over $6 \operatorname{deg} C$ in parts of Russia between the Black Sea and the Arctic. However, eastern North America also cools by about $3 \operatorname{degC}$. The zonal-mean cooling north of $35^{\circ} \mathrm{N}$ is $4.5 \mathrm{degC}$. The temperature change in western Europe is due to cooler air advecting in with the mean winds, while the change over Russia is more likely caused by a change in circulation around the Icelandic Low (see section 3(c)). The cooling in eastern North America is probably caused by a weakening of the pattern, seen in the observations in Fig. 3(b), of transienteddy heat-flux divergence over the Gulf Stream region and convergence over eastern North America. This occurs because the winter ocean heat loss in the Gulf Stream region reduces when the OHT is removed. Thus the OHT warms northern hemisphere winters by a few $\operatorname{deg} C$ in an essentially zonally uniform way while the temperature contrasts across the basins must be explained by other processes.

Figure 10 shows the change in surface air temperature for the case with OHT minus the case without OHT as simulated by the GISS model. The pattern of temperature change is similar to that in the CCM3 model: OHT causes a warming of a few degC that is quite zonally uniform. The remarkable exceptions are that, in the GISS model, where sea-ice cover is allowed to vary, removal of OHT causes an expansion of winter sea ice near Kamchatka and in the Norwegian and Barents Seas that, in turn, causes dramatic cooling (as much as $20 \mathrm{degC}$ ) of the air temperature immediately above and to the east. Nonetheless, it is noticeable how little this subsequently impacts temperatures in Europe 


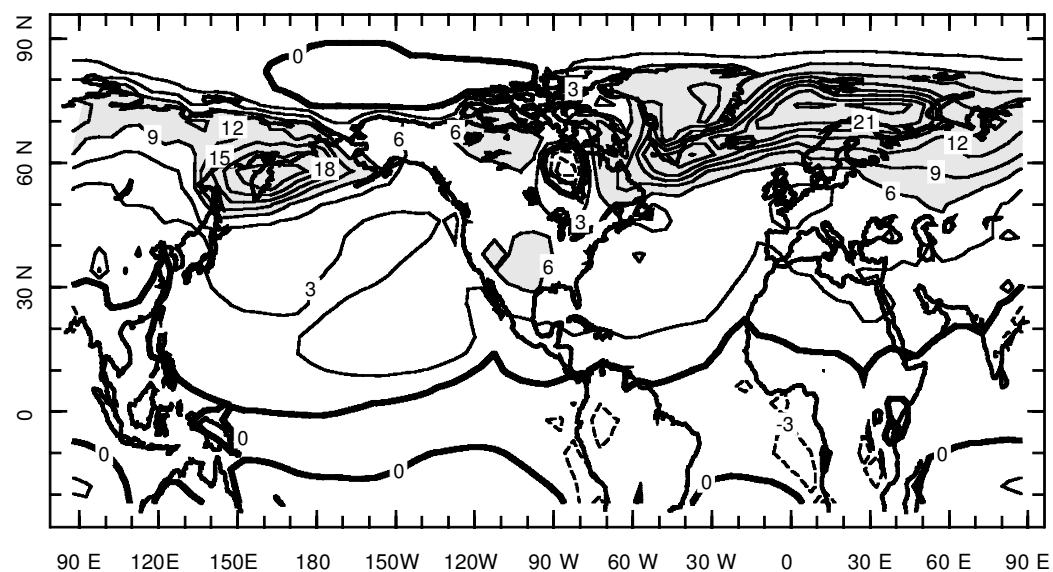

Figure 10. The difference in January surface air temperature as simulated by the GISS AGCM-ML model for the case with a specified OHT minus the case with no OHT (see text). The GISS model allows sea-ice cover to vary. Contours as in Fig. 9.

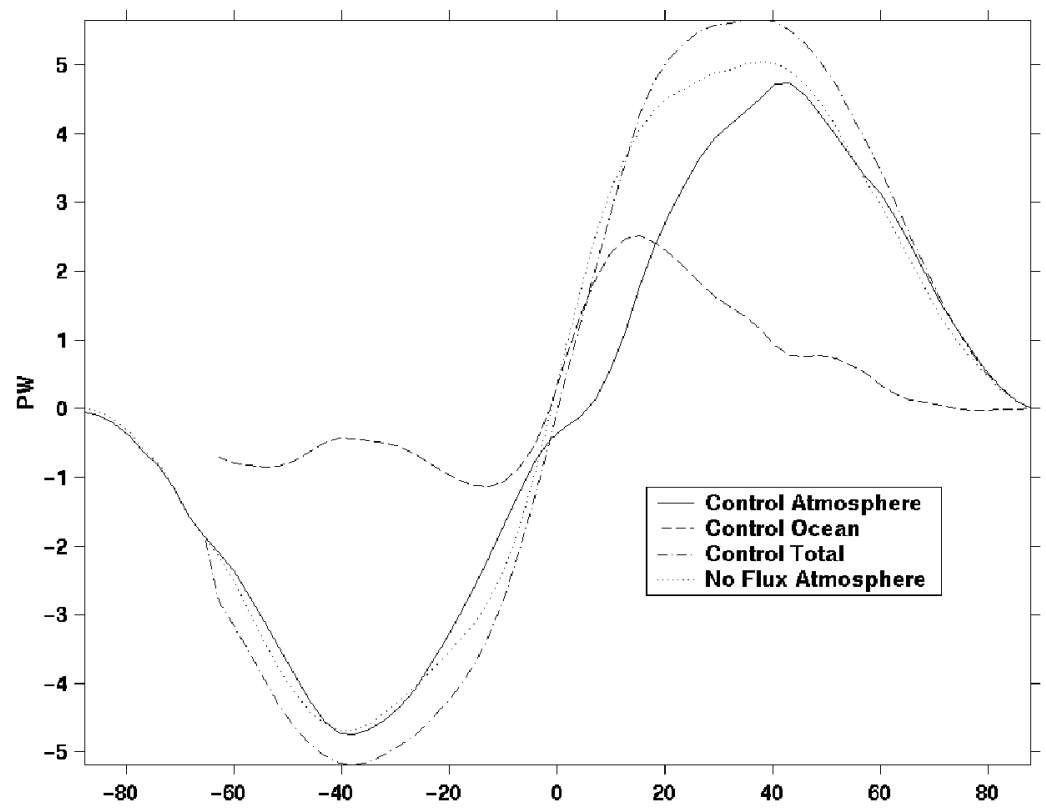

Figure 11. The atmosphere and ocean poleward heat transports, zonally and annually averaged, for the CCM3 AGCM-ML model experiments with and without OHT (see text).

to the south of Norway where the changes are comparable to those simulated by CCM3. The zonal-mean cooling north of $35^{\circ} \mathrm{N}$ is $6 \operatorname{degC}$.

The zonal-mean cooling of $4.5 \mathrm{degC}$ due to removal of OHT in CCM3 is less than anticipated by the simple calculation in the previous section. This is because the atmosphere heat transport partially compensates for the removal of OHT. Figure 11 shows the annual and zonally averaged ocean and atmosphere heat transports for the CCM3 experiments with and without OHT. In the case without OHT the total and atmospheric heat transport are equal. Without OHT, the atmosphere increases its 
(a)

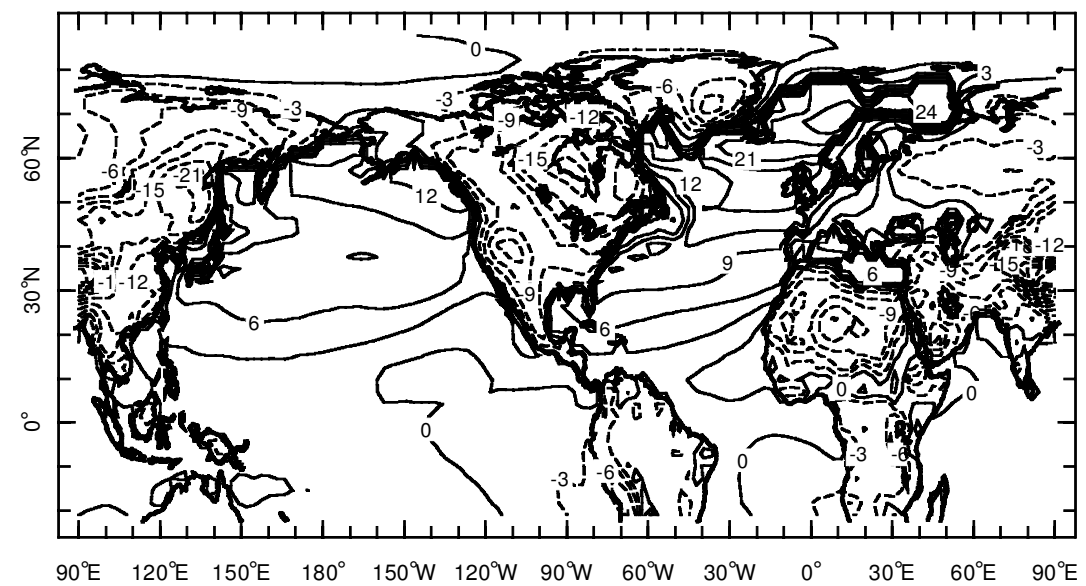

(b)

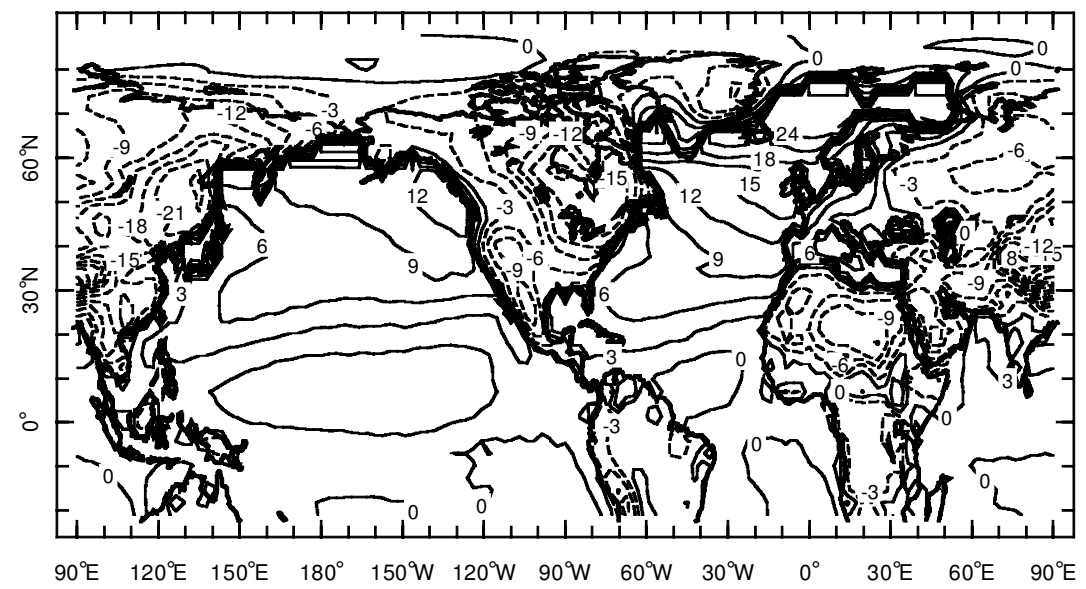

Figure 12. The departure of January surface temperature from the zonal mean as simulated by the CCM3 AGCM-ML model for (a) the case with a specified OHT and (b) the case with no OHT (see text). The contour interval is $3 \operatorname{degC}$ and negative values are dashed.

poleward heat transport in the Tropics and subtropics trying to make up for the loss of the ocean contribution. In midlatitudes north of $40^{\circ} \mathrm{N}$ the atmospheric poleward heat transport changes little when the OHT is removed. Within the GISS model (not shown) the atmosphere also fully compensates in the Tropics, but only partially compensates in midlatitudes, for the loss of OHT.

(b) Contribution of ocean heat transport to the differences in winter temperatures across the North Atlantic

Next we turn our attention to the impact of OHT on the zonal asymmetries of winter temperatures. Figures 12(a) and (b) show the deviation from zonal symmetry of the surface temperature for the two experiments with CCM3. The contrast between European and eastern North American winter temperatures only very slightly weakens when the OHT is removed. When sea ice is allowed to vary, the ocean heat-flux convergence contributes at most $2 \mathrm{degC}$ out of the total contrast of about $15 \mathrm{degC}$ 
(a)

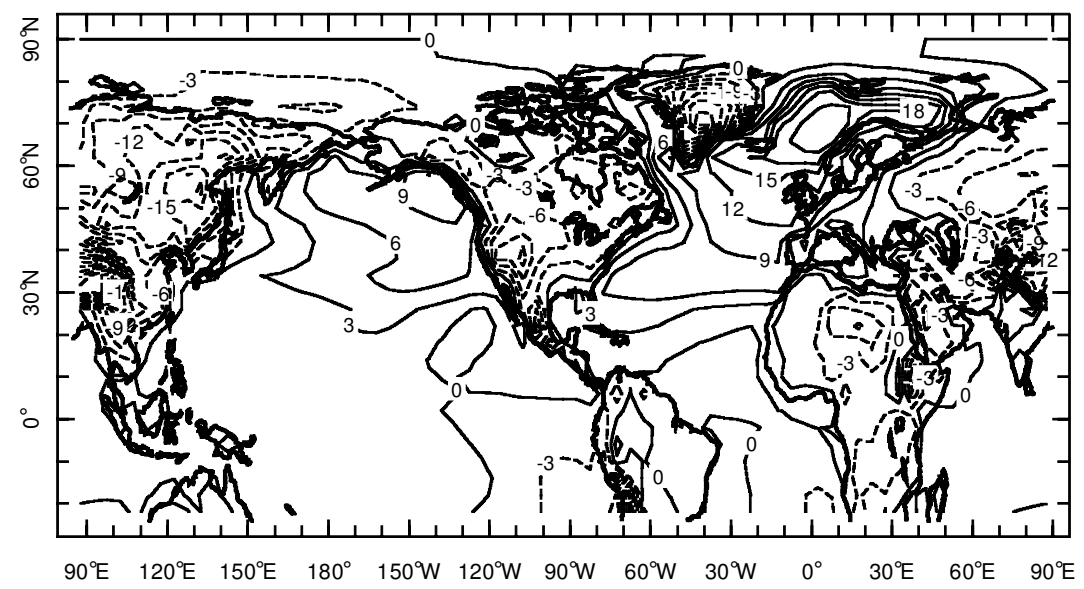

(b)

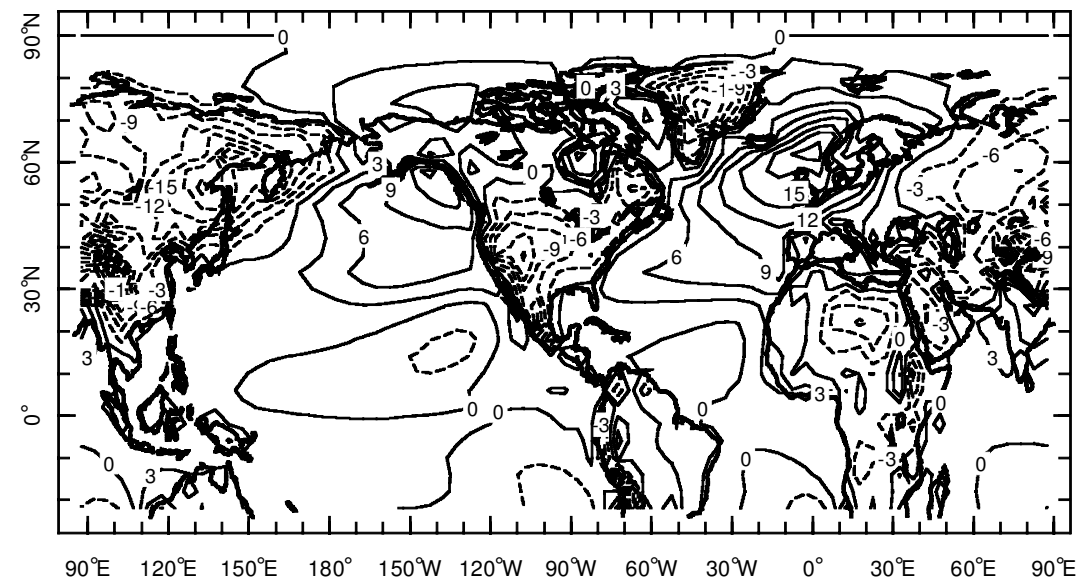

Figure 13. The departure of January surface air temperature from the zonal mean as simulated by the GISS AGCM-ML model, which allows for variations in sea-ice cover, for (a) the case with a specified OHT and (b) the case with no OHT (see text). Contours as in Fig. 12.

south of $60^{\circ} \mathrm{N}$ and about 3-6 degC of the larger $25 \operatorname{deg} \mathrm{C}$ contrast between $60^{\circ} \mathrm{N}$ and $70^{\circ} \mathrm{N}$. Figures $13(\mathrm{a})$ and (b) show the departure from zonal mean of the surface air temperature derived from the GISS model runs with and without OHT. As expected, the zonal variations of surface air temperature are weaker than those of surface temperature (shown for the CCM3 experiments). Nonetheless, the results of the GISS experiments are remarkably similar to those derived from the CCM3 model. Some differences are due to the lower horizontal resolution of the GISS model. The more fundamental difference is that, in the GISS model, expansion of sea ice when the OHT is removed causes the surface air north-west and north of Scandinavia to cool by many degC more than in the CCM3 experiment. Clearly OHT restricts the sea-ice cover in the Norwegian and Barents Seas keeping winters in northern Scandinavia much warmer than they otherwise 
would be. However, this impact is localized and has little impact on the remainder of Europe to the south.

Outside the limited regions influenced by changes in sea-ice cover the similarity of the results of the two models suggests that mixed-layer depth variations are not important to establishing the zonal climate asymmetries. The two models have nothing in common in their physics or numerics. The reproducibility reassures us that the lack of dependence of the zonal asymmetry on OHT is unlikely to be a model artifact.

\section{(c) The shape of the Icelandic Low and the contribution of mountains to the difference in winter temperatures across the North Atlantic}

So far the results are consistent with the difference in winter temperatures across the North Atlantic being determined by the simple contrast between a continental climate in eastern North America and a maritime climate in western Europe. However, it is likely that the exact position and strength of the Icelandic Low, which brings a northerly component to the winds over America and a southerly component over western Europe, is important.

Forcing by orography, asymmetries in the heating of the midlatitude atmosphere at the surface, transient-eddy fluxes and tropical diabatic heating are the principal causes of stationary eddies (see Held (1983) for a review). Held (1983) showed that when mountains were removed in a GCM the flow across the North Atlantic became more zonal. This might be expected to influence the temperature asymmetry. We performed another experiment with the CCM3 AGCM-ML model in which we used the specified q-flux but removed the mountains. (The influence of mountains on surface temperature was the same whether or not we included the q-flux.)

Figure 14 shows the sea-level pressure and the deviation of surface temperature from the zonal mean for the three model experiments with CCM3. In the absence of mountains (Fig. 14(c)), the equivalent barotropic trough over the eastern North American seaboard is considerably weakened compared to the case with mountains (Fig. 14(a)). Consequently, the flow is more zonal over North America, the North Atlantic Ocean and western Europe than when the mountains are present. The weakened northerlies over North America lead to a large warming, while the reduced southerlies over the North Atlantic Ocean and northern Europe cause cooling. The part of the Icelandic Low east of Iceland retains its full strength when the mountains are removed. The difference between Figs. 14(a) and (b) shows the impact of the OHT. In this case the trough over eastern North America remains but the portion of the Icelandic Low east of Iceland is weakened. The flow over western Europe also weakens but becomes more southerly, maintaining the strength of the warm advection. The Icelandic Low comprises an orographically forced trough over eastern North America and a thermally and transient-eddy forced Low north-east of Iceland (e.g. Hoskins and Valdes (1990)). The weakening of the eastern part of the Icelandic Low when OHT is removed is consistent with our estimate that ocean heat-flux convergence accounts for about half of the winter heat release from ocean to atmosphere in this region (Fig. 7). The same weakening occurred in the GISS model (not shown).

Figure 15 shows the effect of mountains on the surface temperature*. The mountains exert a stronger influence on the temperature contrast across the North Atlantic

\footnotetext{
* Some of the surface-temperature difference is caused locally by the change in surface height (e.g. over mountain ranges and plateaux such as Africa) according to a lapse rate, but this does not appreciably influence the contrast between eastern North America and western Europe which both have insignificant topography in the model.
} 


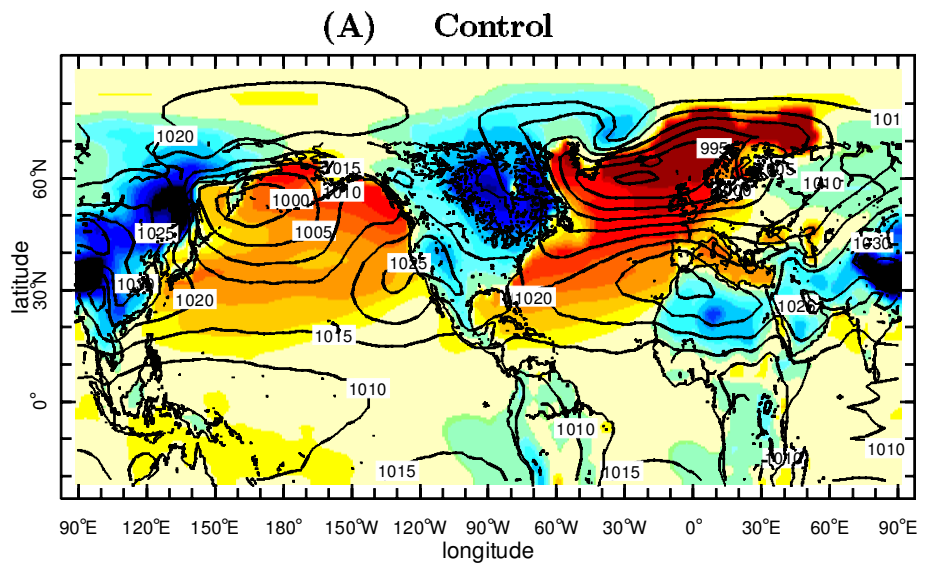

(B) No Flux

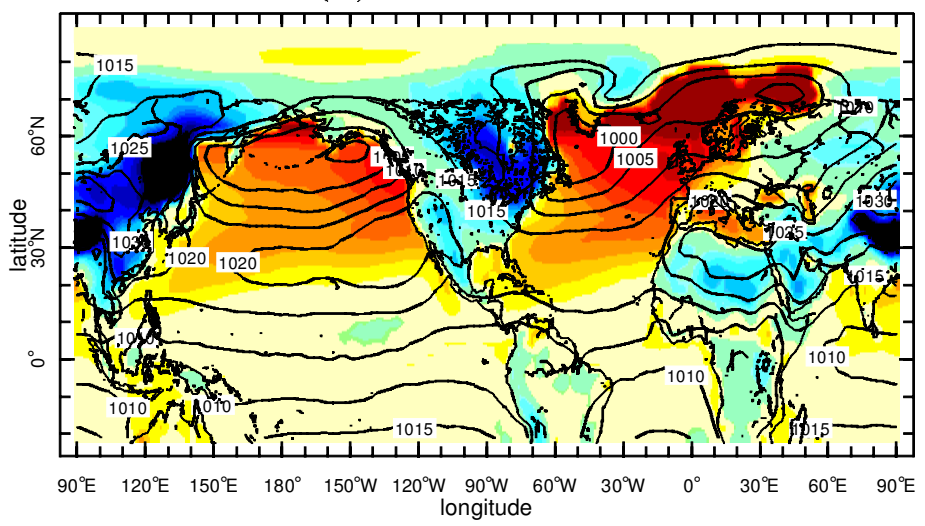

(C) No Mountains
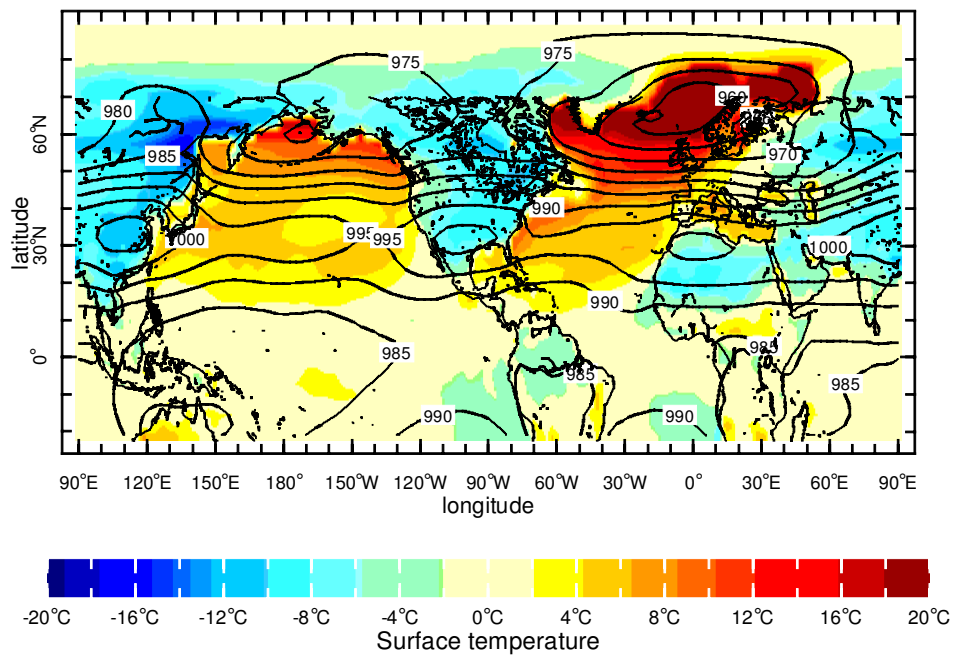

Figure 14. Sea-level pressure (mb) and zonal eddy surface temperature in $\operatorname{degC}$ (colours) for January for (a) the case with mountains and q-flux, (b) the case with mountains and the q-flux set to zero, and (c) the case without mountains but with the q-flux. 


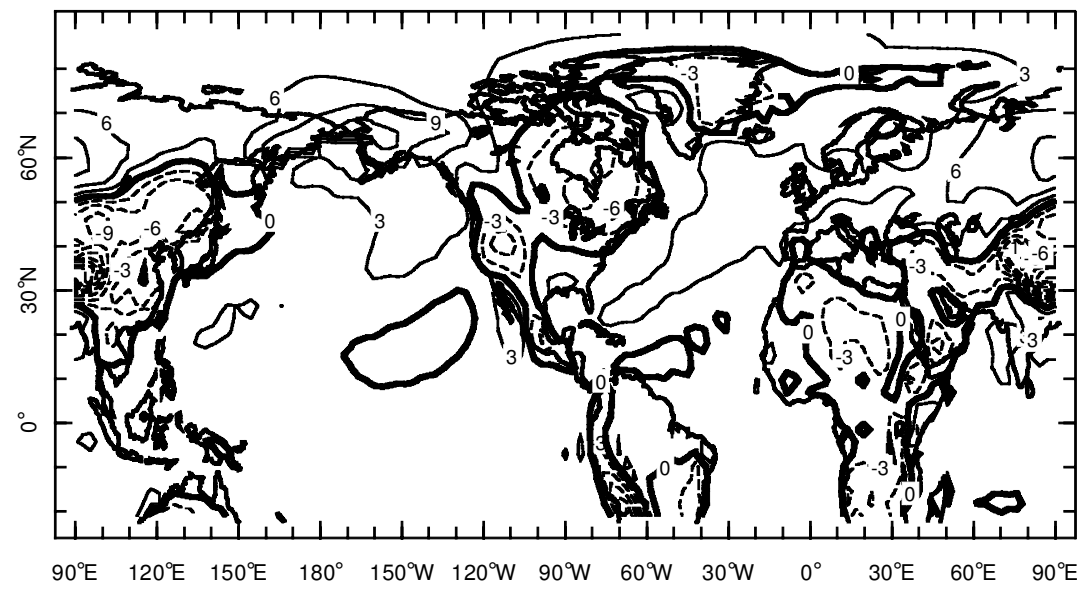

Figure 15. The difference in January surface temperature (degC) for the case with mountains minus the case without mountains, as simulated by CCM3. Both models were run with the specified q-flux.

than does the OHT (compare Fig. 15 with Fig. 9). This is because the OHT generates smaller temperature changes which have the same sign (warming) on both sides of the North Atlantic. In contrast, orography (the Rockies are the dominant influence over the Atlantic sector (Nigam et al. 1988)) creates a large zonal temperature asymmetry, warming the British Isles and parts of Scandinavia by as much as $3 \mathrm{deg} C$ and cooling North America by as much as $6 \mathrm{degC}$. Hence, the model results indicate about half of the 15-20 degC difference in wintertime temperature between western Europe south of $60^{\circ} \mathrm{N}$ and eastern North America is due to the net forcing of the atmospheric stationary waves by orography (the other half is due to the continental-maritime contrast plus advection by the thermally forced stationary waves). The net effect of orography greatly exceeds the direct mechanical forcing of the flow by the mountains and also includes the indirect effects of the reorganization of the patterns and amplitudes of the forcing of the stationary waves by transient eddies and diabatic heating.

\section{(d) The contrast between the maritime air temperatures of western Europe and western Canada and Alaska}

North of about $40^{\circ} \mathrm{N}$ there is considerably more poleward OHT in the Atlantic Ocean than in the Pacific Ocean because of the contribution of the thermohaline circulation which has its sinking branch in the North Atlantic (e.g. Broecker 1997). While poleward OHT does not contribute strongly to the east-west asymmetry of winter temperatures across the oceans, is it the cause of the noticeable difference in temperatures between the west coasts of Europe and North America?

Table 1 lists the difference in January surface air temperatures, Atlantic minus Pacific, at various latitudes along the west coasts of Canada and Alaska and in the British Isles and Norway, for observations and the CCM3 and GISS model runs with and without OHT. At $50^{\circ} \mathrm{N}$ (Cornwall in Europe and Vancouver Island in Canada) the observed surface air temperature from NCEP is $5 \operatorname{degC}$ warmer in Europe than Canada. At $55^{\circ} \mathrm{N}$ (Donegal in Ireland and Prince of Wales Island in Alaska) the difference is $5 \operatorname{degC}$ and at $60^{\circ} \mathrm{N}$ (just south of Bergen in Norway and Icy Bay in Alaska) the difference is $7 \operatorname{deg} C$. These temperature differences are reasonably well simulated in the GISS and CCM3 model runs accounting for the OHT. In the experiments without OHT these differences between the Atlantic and the Pacific are maintained. Hence, at 
TABLE 1. ATLANTIC MinUs PACIFIC NEAR SURFACE COASTAL AIR TEMPERATURE (degC)

\begin{tabular}{cccccccc}
\hline & & \multicolumn{2}{c}{ GISS-ML } & & \multicolumn{2}{c}{ CCM3-ML } \\
\cline { 3 - 4 } \cline { 6 - 7 } & Observations & OHT & no OHT & & OHT & no OHT \\
\hline $60^{\circ} \mathrm{N}$ & 7 & 11 & 10 & & 9 & 10 \\
$55^{\circ} \mathrm{N}$ & 5 & 4 & 7 & & 7 & 8 \\
$50^{\circ} \mathrm{N}$ & 5 & 5 & 6 & & 6 & 5 \\
\hline
\end{tabular}

OHT $=$ ocean heat transport. The Models GISS-ML and CCM3-ML are explained in the text.

least in these models, heat transport by the thermohaline circulation is not required for maritime Europe to be warmer than the Pacific coast of Canada and Alaska.

So why is the Atlantic coast of north-west Europe warmer than the Pacific coast of north-west America? A full explanation of this temperature contrast is beyond the scope of the current work but our GCM experiments indicate that OHT and orographic forcing are not responsible for this asymmetry, because the asymmetry remains in the experiments with no OHT and with no mountains. The difference in SSTs between the two coasts is actually less than the difference in surface air temperature, suggesting that the coastal regions of north-western America have more continental influence than the coastal regions of north-western Europe. The more fundamental reason must be the different geographies of the two basins. The open ocean stretching north-east north of $60^{\circ} \mathrm{N}$ in the Atlantic means that the Icelandic Low is placed further north than the Aleutian Low. It also extends further into the eastern part of the ocean basin. This arrangement favours warming south-westerly winds that sweep across the maritime areas of north-west Europe and which have no counterpart on the Pacific coast of North America at the same latitudes.

\section{POSSIBLE SENSITIVITY OF RESULTS TO MODEL ERRORS AND ASSUMPTIONS}

We have used two independent atmospheric GCMs coupled to different mixed-layer oceans and with different treatments of sea ice. In the CCM3 model the ocean mixed layer has a fixed depth and the q-flux accounts for OHT as well as the effects of heat exchange with layers below that occurs in nature as the mixed-layer depth varies. In the GISS model the mixed-layer depth variations are specified and the q-flux more closely accounts for OHT alone. Comparison of the results demonstrates that the treatment of the mixed layer does not substantially affect the results, except in western boundary currents where winter heat loss is opposed by mixed-layer deepening. In these regions the GISS model, which better accounts for entrainment than does the CCM3 mixed-layer model, cools less than CCM3 when the q-flux is removed. The next step of inclusion of a fully interactive mixed layer is unlikely to change the main results presented here.

More problematic for certain regions is the treatment of sea ice. In CCM3 we held the ice cover fixed, but when it was allowed to vary in the GISS model removal of OHT caused a large expansion of seasonal ice cover in the Kamchatka region and in the Norwegian and Barents Seas, cooling the air above and to the east. The thermodynamic sea-ice model in the GISS GCM probably overestimates the increase in sea-ice extent. (A more reliable estimate requires a dynamic ice model that accounts for the drift of sea ice by winds.) The GISS and CCM3 models probably bracket the influence of sea ice and demonstrate that the impact of changes in ice extent on winter temperatures is regional, not influencing temperatures in western Europe south of southern Norway. 
The north-eastern part of the Icelandic Low in CCM3 extends too far east into northern Europe which could, perhaps, mean that, as this part weakens when OHT is removed, the impact on winter temperatures also extends too far east. The structure of the Icelandic Low is better represented in the GISS model, with strong pressure gradients parallel to the north-west European coast. Comparison of the results of the two models indicates that these differences in simulation of the Low have little impact on the main results presented here, certainly less impact than the treatment of sea ice.

Finally a comment is in order concerning the statistical significance of the results presented. The temperature changes caused by removal of OHT in the models are robust. Over the midlatitude oceans they correspond to several standard deviations of the internal variability (estimated from the control runs). The temperature changes over land are more typically the same size as the internal variability. However, by looking at the individual years, we found that in all regions of noticeable change (more than 2 degC) removal of OHT causes a cooling relative to the control run in almost every single winter, indicating the robustness of the results despite the relatively short periods of integration.

Together these considerations argue that the main results presented here are not sensitive to the peculiarities of the models used and that improvements in aspects of the models will change the results only locally.

\section{CONCLUSIONS}

We have sought to explain why winters in western Europe are much milder than those in eastern North America and other places at the same latitude. The principal findings are as follows.

(i) Experiments with atmospheric GCMs, coupled to mixed-layer oceans in which the OHT is either accounted for or not, indicate that OHT warms winters over land in a quite zonally uniform way and warms the North Atlantic Ocean itself by much more. In the case where the sea-ice cover is held fixed, the area average warming of the area north of $35^{\circ} \mathrm{N}$ caused by the global OHT $\left(1.3 \mathrm{PW}\right.$ across $35^{\circ} \mathrm{N}$ in the annual mean, taken to be an upper bound on the winter value) is $4.5 \mathrm{degC}$. The warming would be larger but the atmosphere heat transport partially compensates for the imposed change in OHT. This warming contrasts with the $27 \mathrm{degC}$ area average warming due to the larger atmospheric heat transport (about $6 \mathrm{PW}$ across $35^{\circ} \mathrm{N}$ in winter) and another $27 \mathrm{degC}$ area average warming due to the seasonal ocean heat storage and release. When sea ice was allowed to vary in one of the models, removal of OHT caused the area average warming north of $35^{\circ} \mathrm{N}$ to increase to $6 \mathrm{degC}$ as sea ice extended in the Norwegian and Barents Seas, greatly cooling the air above and to the east. However, the impact on winter temperatures south of $60^{\circ} \mathrm{N}$ was small. These results are broadly consistent with prior results (e.g. Manabe and Stouffer (1988); Rind et al. (2001)) that probably also overestimated the increase in sea-ice cover (see previous discussion).

(ii) In contrast, the difference in winter temperatures between western Europe and eastern North America can exceed $15 \mathrm{degC}$ and, in the models, is hardly affected by the OHT except at the latitude of northern Norway. This contrast is explained by interactions between atmospheric advection and the seasonal storage and heat release by the ocean. This is consistent with observational evidence that the winter heat release from the North Atlantic Ocean to the atmosphere is primarily sustained by seasonal heat release while ocean heat-flux convergence contributes significantly only in the western boundary current region east of the United States and in the area north of Norway. 
(iii) Advection by the stationary waves - the Icelandic Low over the North Atlantic Ocean-adds to the effect of zonal advection of the land-sea temperature contrast by bringing cold north-westerlies to eastern North America and mild south-westerlies to western Europe.

(iv) The Icelandic Low is forced thermally and by the net effects of orography, which are the result of a complicated interplay between the direct (mechanical) effect of orographic forcing, the transient fluxes, and diabatic heating. Further model experiments indicate that the net effect of orography intensifies the trough over the western North Atlantic that brings cold north-westerlies into eastern North America and warm south-westerlies to western Europe. This accounts for almost half of the observed winter temperature contrast between these areas. Advection by the sum of the zonal-mean westerlies and the thermally forced stationary waves - as diagnosed in a model experiment with no mountains-accounts for the other half of the observed temperature contrast across the North Atlantic Ocean.

(v) In all the model experiments the Atlantic coast of Europe remained much warmer than the Pacific coast of Canada and Alaska when the OHT was removed, as both areas cooled by similar amounts. The Atlantic-Pacific contrast ( 5 to $7 \mathrm{degC}$ ) is larger than can be accounted for by OHT and must be a consequence of the pattern of atmospheric heat transport. It probably arises because the different geographies of the two oceans allow less continental influence at the European coast than at the American coast and causes the Icelandic Low to adopt a more northerly position, and extend further into the eastern part of the basin, than the Aleutian Low.

In conclusion, while OHT warms winters on both sides of the North Atlantic Ocean by a few $\operatorname{degC}$, the much larger temperature difference across the ocean, and that between the maritime areas of north-western Europe and western North America, are explained by the interaction between the atmospheric circulation and seasonal storage and release of heat by the ocean. Stationary waves greatly strengthen the temperature contrast across the North Atlantic and are themselves heavily influenced by the net effect of orography. In contrast, transport of heat by the ocean has a minor influence on the wintertime zonal asymmetries of temperature. Even in the zonal mean, OHT has a small effect compared to those of seasonal heat storage and release by the ocean and atmospheric heat transport. In retrospect these conclusions may seem obvious, but we are unaware of any published explanation of why winters in western Europe are mild that does not invoke poleward heat transport by the ocean as an important influence that augments its maritime climate.

\section{ACKNOWLEDGEMENTS}

This work was supported by NOAA grant UCSIO -10775411D/NA47GP0188(The Consortium on the Ocean's Role in Climate) and NSF grant ATM-9986515. DSB and JY were supported by a grant from NOAA's Office of Global Programs. Jennifer Miller and Ben Kerman helped prepare the figures. We particularly want to thank Yochanan Kushnir for many excellent conversations. We also thank Martin Visbeck, Brian Hoskins, Stefan Rahmstorf and Andrew Weaver for useful conversations and the two anonymous reviewers for constructive criticisms. We thank Jim Hansen for providing us with access to the GISS model, Kenneth Lo for performing the GISS model integrations and Gary Russell for helping in interpretation of the model output. This is Lamont Doherty Earth Observatory contribution number 6322. 
Bjerknes, J.

Boning, C. W. and Herrmann, P.

Broecker, W. S.

Chassignet, E. P., Smith, L. T., Bleck, R. and Bryan. F. O.

Clement, A. C. and Seager. R.

Da Silva, A., Young, A. C. and Levitus, S.

Del Genio, A. D., Yao, M.-Y., Kovari, W. and Lo, K. W.

Ganachaud, A. and Wunsch, C.

Gill, A. E. and Niiler, P.

Hansen, J., Lacis, A., Rind, D., Russell, G., Stone, P., Fung, I., Ruedy, R. and Lerner, J.

Hartmann, D. L.

Held, I. M.

Hoskins, B. J. and Karoly, D. J.

Hoskins, B. J. and Valdes, P. J.

Houghton, H. G.

Hsiung, J., Newell, R. E. and Houghtby, T.

Josey, S. A., Kent, E. C. and Taylor, P. K.

Kalnay, E. M., Kanamitsu, M., Kistler, R., Collins, W., Deaven, D., Gandin, L., Iredell, M., Saha, S., White, G., Woollen, J., Zhu, Y., Chelliah, M., Ebisuzaki, W., Higgins, W., Janowiak, J., Mo, K. C., Ropelewski, C., Wang, J., Leetmaa, A., Reynolds, R., Jenne, R. and Joseph, D.

Kiehl, J. T., Hack, J. J., Bonan, G. B., Boville, B. A., Williamson, D. L. and Rasch, P. J.

Latif, M. J., Roeckner, E., Mikolajewicz, U. and Voss, R. Lau, N.-C.

Levitus, S. E. and Boyer, T.

Manabe, S. and Stouffer, R. J.

Maury, M. F.
1981

1964

1994

1997

1996

1999

1994

1994

1983

1954

1989

1998

1996

\section{REFERENCES}

Atlantic air-sea interaction. Adv. Geophys., 10, 1-82

Annual cycle of poleward heat transport in the ocean: Results from high-resolution modeling of the North and equatorial Atlantic. J. Phys. Oceanogr., 24, 91-107

Thermohaline circulation, the Achilles heel of our climate system: Will man-made $\mathrm{CO}_{2}$ upset the climate balance? Science, 278, 1582-1588

A model comparison: Numerical simulation of the North and equatorial Atlantic oceanic circulation in depth and isopycnic coordinates. J. Phys. Oceanogr., 26, 1849-1867

Climate and the tropical oceans. J. Climate, 12, 3383-3401

Atlas of surface marine data 1994, Volume 1. Algorithims and Procedures, National Oceanographic and Atmospheric Administration, Dept. of Commerce, Washington DC

A prognostic cloud water parameterization for global climate models. J. Climate, 9, 270-304

Improved estimates of global ocean circulation, heat transport and mixing from hydrographic data. Nature, 408, 453-457

The theory of seasonal variability in the ocean. Deep Sea Res., 20, 141-177

'Climate sensitivity: Analysis of feedback mechanisms'. Pp. 130163 in Climate processes and climate sensitivity. Geophysical Monograph 29. American Geophysical Union, Washington DC

Global physical climatology, Academic Press, New York

'Stationary and quasi-stationary eddies in the extratropical troposphere: Theory'. Pp. 127-168 in Large-scale dynamical processes in the atmosphere. Eds. B. J. Hoskins and R. P. Pearce. Academic Press, London

The steady linear response of a spherical atmosphere to thermal and orographic forcing. J. Atmos. Sci., 38, 1179-1196

On the existence of storm tracks. J. Atmos. Sci., 47, 1854-1864

On the annual heat balance of the northern hemisphere. J. Meteorol., 11, 1-9

The annual cycle of oceanic heat storage and oceanic meridional heat transport. Q. J. R. Meteorol. Soc., 115, 1-28

The Southampton Oceanography Centre (SOC) oceanatmosphere heat, momentum and freshwater flux atlas. Southampton Oceanography Centre, Southampton, UK

The NCEP/NCAR 40-year reanalysis project. Bull. Am. Meteorol. Soc. , 77, 437-471

The National Center for Atmospheric Research Community Climate Model: CCM3. J. Climate, 11, 1131-1149

Tropical stabilization of the thermohaline circulation in a greenhouse warming simulation. J. Climate, 13, 1809-1813

The observed structure of tropospheric stationary waves and the local balances of vorticity and heat. J. Atmos. Sci., 36, 9961016

World ocean atlas 1994, Volume 4: Temperature. NOAA Atlas NESDIS 4, US Dept. of Commerce, Washington DC

Two stable equilibria of a coupled ocean-atmosphere model. J. Climate, 1, 841-866

The physical geography of the sea and its meteorology. Harper and Brothers, New York 
Nigam, S., Held, I. M. and Lyons, S. W.

Oberhuber, J. M.

Peixoto, J. P. and Oort, A. H.

Rind, D., deMenocal, P.,

Russell, G., Sheth, S.,

Collins, D., Schmidt, G. and Teller, J.

Russell, G. L., Miller, J. R. and Tsang, L.-C.

Smagorinsky, J.

Sverdrup, H. U.

Trenberth, K. E. and Caron, J. M.

Trenberth, K. E., Caron, J. M. and Stepaniak, D. P.
1988

1988

1992

2001
Linear simulation of the stationary eddies in a GCM. Part II: Mountain model. J. Atmos. Sci., 45, 1433-1452

An atlas based on the COADS dataset: The budgets of heat, buoyancy and turbulent kinetic energy at the surface of the global ocean. Max Planck Institut für Meteorologie, Hamburg, Germany

The physics of climate. American Institute of Physics, New York Effects of glacial meltwater in the GISS coupled atmosphereocean model. Part I: North Atlantic deep water response. J. Geophys. Res. Atmos., 106, 27335-27354

Seasonal oceanic heat transports computed from an atmospheric model. Dyn. Atmos. Oceans, 9, 253-271

The dynamical influence of large-scale heat sources and sinks on the quasi-stationary mean motions of the atmosphere. Q. J. R. Meteorol. Soc., 79, 342-366

Transport of heat by the currents of the North Atlantic and North Pacific Oceans. Festskrift til Professor Bjorn HellandHansen. Naturen, Bergen, Norway 226-236

Estimates of meridional atmosphere and ocean heat transports. J. Climate, 14, 3433-3443

The atmospheric energy budget and implications for surface fluxes and ocean heat transports. Clim. Dyn., 17, 259-276 